\title{
PRODUÇÃO DE BANANEIRA 'GRANDE NAINE' SUPERADENSADA E IRRIGADA NO VALE DO SÃO FRANCISCO
}

\author{
Yield of banana irrigated "Grande Naine" with high densities in São Francisco River Valley \\ José Egídio Flori ${ }^{1}$, Geraldo Milanez de Resende ${ }^{1}$, Lázaro Eurípides Paiva ${ }^{1}$
}

\begin{abstract}
RESUMO
Conduziu-se este experimento com o objetivo de avaliar o efeito do adensamento de plantas na produtividade de cultura da bananeira 'Grande Naine' em condições irrigadas no vale do Submédio São Francisco, Juazeiro, Brasil. O experimento foi conduzido em blocos casualizados com cinco tratamentoss e três repetições em solo tipo Vertissolo, nos espaçamentos: $\mathrm{T}_{1}=3,75 \times 1,25 \times 2, \mathrm{~m}\left(2.000 \mathrm{pl}^{-h^{-1}}\right), \mathrm{T}_{2}=3,75 \times 1,25 \times 1 \mathrm{~m}\left(4.000 \mathrm{pl}^{-h^{-1}}\right), \mathrm{T}_{3}=3,75 \times 1,25 \times 0,66 \mathrm{~m}(6.060$ pl.ha $\left.{ }^{-1}\right) ; \mathrm{T}_{4}=3,75 \times 1,25 \times 0,50\left(8.000 \mathrm{pl} \mathrm{ha}^{-1}\right), \mathrm{T}_{5}=3,75 \times 1,25 \times 2 \mathrm{~m}\left(2.000 \mathrm{pl} \cdot \mathrm{ha}^{-1}\right)$, sendo $3,75 \mathrm{~m}$ entre fileiras duplas, $1,25 \mathrm{~m}$ entre linhas e $2 \mathrm{~m}, 1 \mathrm{~m}, 0,5 \mathrm{~m}$ e $0,66 \mathrm{~m}$ entre plantas nas linhas. Avaliaram-se dois ciclos de produção com base nas seguintes características: diâmetro do pseudocaule (DP) a $30 \mathrm{~cm}$ do solo, altura da planta (AP), massa do cacho (MC), número de pencas (NP), número de frutos (NF), massa do engaço (MI), comprimento do fruto (CF), diâmetro do fruto (DF), massa do fruto (MF), ciclo vegetativo (CV) (plantio até a colheita), rendimento ha ${ }^{-1}\left(\mathrm{Rha}^{-1}\right)$, rendimento $\left(\mathrm{R} \mathrm{ha}^{-1} \mathrm{ano}^{-1}\right)$. No

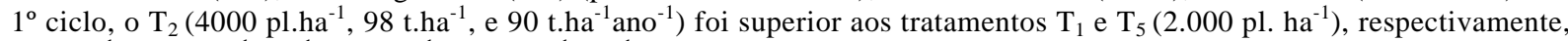
65 t.ha ${ }^{-1}$ e 66 t.ha ${ }^{-1}$ ano $^{-1}, 69$ t.ha $^{-1}$ e 68 t.ha $^{-1}$ ano $^{-1}$. No $2^{\circ}$ ciclo, não houve diferença entre os tratamentos em relação ao rendimento por hectare. Observou-se que os tratamentos $T_{1}, T_{2}$ e $T_{5}$, no $2^{\circ}$ ciclo, foram superiores ao $T_{4}$ em termos de rendimento ha $^{-1}$ ano $^{-1}$ e qualidade dos frutos.
\end{abstract}

Termos para indexação: Espaçamento, fila dupla, rendimento.

\section{ABSTRACT}

The objective of this work was to verify the influence of the density on yield of the banana 'Grande Naine', planted in Juazeiro, BA, Brazil. Four densities (2000, 4000, 6000 e 8000 plants ha-1) at systems double rows were evaluated for first and second crops cycle. Banana suckers were planted at $\mathrm{T}_{1}=3.75 \times 1.25 \times 2 \mathrm{~m}\left(2.000 \mathrm{pl}^{-h^{-1}}\right) ; \mathrm{T}_{2}=3.75 \times 1.25 \times 1 \mathrm{~m}\left(4.000 \mathrm{pl}^{-h a^{-1}}\right)$; $\mathrm{T}_{3}=3.75 \times 1.25 \times 0,66 \mathrm{~m}\left(6.000 \mathrm{pl}^{-h^{-1}}\right) ; \mathrm{T}_{4}=3.75 \times 1.25 \times 0,50\left(8.000 \mathrm{pl}^{-h^{-1}}\right) ; \mathrm{T}_{5}=3.75 \times 1.25 \times 2 \mathrm{~m}\left(2.000\right.$ pl.ha $\left.^{-1}\right)$, respectively between double rows, between inter rows and distance among plants in rows. The characteristic availed were diameter (PD) and height $(\mathrm{PH})$ of plant, mass of bunch (BM), number of hands (HN), number of fruit (FN), mass of stem/bunch (RM), length of fruit (FL), diameter of fruit (FD), mass of fruit (FM), cycle crop (CC), yield per ha and yield per ha per year of crop. The yield in the first cycle $\mathrm{T}_{2}$ (4.000 $\mathrm{pl}^{-h^{-1}}$ ) was higher than at the yield of T1 and T5 $\left(2.000 \mathrm{pl}^{-h^{-1}}\right)$. On the second cycle does not were difference significance among the treatments. The yield and quality de fruit from $T_{1}, T_{2} e T_{5}$ and were best than the $T_{3} \mathrm{e}_{4}$

Index terms: Spacing, double row, yield

(Recebido para publicação em 3 de outubro de 2003 e aprovado em 1ำ de junho de 2004)

\section{INTRODUÇÃOO}

Devido a sua ampla adaptação, a bananeira é cultivada em quase todos os países tropicais. Segundo a FAO (2001), em 2000, o principal produtor foi a Índia, seguida do Equador e Brasil, respectivamente, com $13,9,6,8$ e 6,3 milhões de toneladas. Os países que se destacam no cenário mundial da bananicultura são: Costa Rica, Equador, Índia e Colômbia, os quais se situam entre os que têm os maiores produtividades e maiores volumes de produção da fruta. Entre os maiores exportadores, destacam-se: Equador, Costa Rica, Colômbia e Filipinas, respectivamente, com $4.056 .141,2.557 .000,1.855 .675,1.319 .632$ tone ladas de frutos. Os principais importadores são EUA, Alemanha, Bélgica, Luxemburgo e Japão, respectivamente, com 4.507.919; 994.925; 988.925 e 983.204 toneladas.

O cultivo da bananeira talvez seja o único cultivo comercial realizado na maioria dos municípios brasileiros. A banana e a laranja são as frutas mais consumidas pela população, porque estão disponíveis nos mercados a preços razoáveis e em quantidades suficientes em todos os meses do ano, além, é claro, das suas importâncias nutricionais para a população. Os nove maiores Estados produtores são: São Paulo (1.178.405 t), Bahia $(764.707$ t), Pará (697.812 t), Santa Catarina

1. Pesquisador Embrapa Semi-Árido. BR 428, km 152 - Zona Rural - Caixa Postal 23 - 56300-000 - Petrolina, PE.

Ciênc. agrotec., Lavras, v. 28, n. 5, p. 1060-1065, set.out., 2004 
(643.500 t), Minas Gerais (547.267 t), Pernambuco (427.495 t), Ceará (349.864 t), Paraíba (303.008 t) e Rio de Janeiro (175.072 t) (AGRIANUAL, 2004).

A bananeira é uma planta tipicamente tropical, exigindo calor constante e elevada umidade para seu bom desenvolvimento. As condições favoráveis ao seu cultivo são normalmente encontradas na faixa compreendida entre os paralelos de $30^{\circ}$ de Latitude Norte e Sul, cuja temperatura situa-se entre os limites de $10^{\circ} \mathrm{C}$ e $40^{\circ}$ $\mathrm{C}$; entretanto, existe a possibilidade de seu cultivo em latitudes acima de $30^{\circ} \mathrm{C}$, desde que a temperatura não seja um fator limitante, ou seja, média mínima abaixo de $11^{\circ} \mathrm{C}$ e/ou ocorrência de geadas ocasionais (MOREIRA, 1995).

Os produtores de bananeira do Estado do Piauí utilizam o adensamento como alternativa para reduzir a vida útil do bananal para duas ou três safras, como meio para enfrentarem os problemas de ataque de sigatoka amarela e, dessa forma, não utilizam o controle químico. Em termos de eficiência agronômica, esses produtores estão aproveitando as vantagens da técnica do adensamento que é maior produtividade no primeiro e segundo ciclos, sem perda significativa da qualidade comercial dos frutos, como verificada nos trabalhos de Silva e Campos (1975), Gomes (1984), Belalcázar Carvajal (1991), Soto Ballestero (1992), Lichtemberg et al. (1994) e Scarpare Filho e Kluge (2001).

Tem sido verificado que o aumento da densidade eleva a produção por hectare, em razão do grande número de cachos colhidos Robinson e Nel (1986) e Lichtemberg et al. (1997). Entretanto, considerando que a bananeira não apresenta ciclo anual definido, a produtividade medida em t ha ${ }^{-1}$ ano $^{-1}$ é progressivamente reduzida com o incremento da densidade e com a evolução dos ciclos (ROBINSON e NEL, 1986; LICHTEMBERG et al., 1997).

Devido à consideração anterior sobre as comparações e análises estatísticas de experimentos de densidade populacional, é importante padronizar o tempo de produção. Isso se faz com a aplicação de uma fórmula: $\mathrm{P}^{*} \mathrm{t} / \mathrm{T}$, em que $\mathrm{P}=$ produção por área $\left(\mathrm{t} \cdot \mathrm{ha}^{-1}\right), \mathrm{t}=\mathrm{o}$ período de 12 meses e $\mathrm{T}=\mathrm{o}$ tempo de produção no campo (meses). Entretanto, em avaliações de superadensamento, o importante será a rentabilidade do cultivo (maior retorno financeiro líquido), porque a maior produtividade compensará o alongamento do ciclo. Nesse caso, a maior produtividade será vantajosa, se não interferir na qualidade do fruto para o mercado a que se destina, ou seja, a partir do ponto que se combine melhor produtividade com a qualidade mínima de mercado. A maior rentabilidade nos cultivos adensados foi constatada por
Robinson e Nel (1986), Belalcázar Carvajal (1991) e Anil et al. (1994).

Ao se analisarem economicamente os cultivos com adensamento, também se observa essa vantagem para essa técnica de cultivo. Estudos citados por Belalcázar Carvajal (1991) registraram a comparação da taxa interna de retorno (TIR) em cultivos adensados de bananeira de 1666, 3332 e 5000 plantas ha $^{-1}$, calculada trimestralmente, e concluíram para o $1^{\circ}$ ciclo que as melhores densidades foram de 5000 e 3333 plantas ha $^{-1}$, respectivamente, com $3,86 \%$ e $3,21 \%$ contra $1,05 \%$ para a densidade de 1666 plantas ha $^{-1}$. Anil et al. (1994), testando densidades variando de 1975 a 6400 plantas/ha da cv. Nendran (AAB) no $1^{\circ}$ ciclo, encontraram o melhor retorno líquido financeiro no espaçamento de 1,75 x $1,75 \mathrm{~m}$ (3265 plantas/ha), sem comprometer a qualidade comercial dos frutos. Os resultados de Robinson e Nel (1986), $1^{\circ}$ ciclo, corroboram os resultados de Anil et al. (1994), em que a densidade de 3333 plantas/ha resultou no melhor retorno econômico. Esses autores também verificaram que a densidade de 5555 plantas/ha obteve o maior rendimento comerciável estimado por ano.

A técnica de adensamento constitui-se em considerar a cultura da bananeira não como semi-perene (exploração tradicional) e sim, como uma cultura anual ou bianual, ou seja, aproveita-se uma ou duas safras e replanta-se toda a cultura nos cultivos seguintes.

Sabe-se que os arranjos de espaçamentos triangulares e retangulares e mesmo os quadrados são mais eficientes agronomicamente do que os de fila dupla, porque permitem melhor distribuição espacial, com ganhos no aproveitamento da luminosidade pela planta (SOTO BALLESTERO, 1992). Entretanto, o sistema de fileira dupla é amplamente utilizado em regiões irrigadas onde se utiliza o sistema de irrigação localizada do tipo microaspersão e gotejamento, porque esses sistemas diminuem o custo de implantação da cultura.

Ainda a favor do adensamento, particularmente para a região do Submédio São Francisco, tem-se na combinação de adensamento com cultivo anual a minimização de danos causados por fortes ventos nessa região do nordeste brasileiro. Os ventos fortes, que têm causado prejuízos consideráveis nessa região nos últimos cinco anos, têm ocorrido em épocas prédeterminadas (nov. a fev.). Observou-se que muitos bananais, no primeiro ciclo, e com plantas sem florescimento à época dos vendavais, resistiram melhor à queda (FLORI, 1998 - Comunicação Pessoal José Egídio Flori. Pesquisador Embrapa Semi-Arido, Petrolina, PE.). Nessas condições, o cultivo da bananeira, com direcio- 
namento da época de plantio e previsão de florescimento e colheita para fora das épocas prováveis de ocorrência de ventos, pode ser um recurso extra para salvar muitos bananais da região. Levantamentos feitos pela CODEVASF de Petrolina - PE, contabilizaram um prejuízo da ordem de R\$13.000.000,00 (treze milhões de reais) em aproximadamente 2.596 ha de bananeira no município de Petrolina, PE, devido à ação dos vendavais ocorridos em novembro de 1997 e fevereiro de 1998 (ROSA JÚNIOR et al., 2000).

Tendo em vista a possibilidade de diminuição dos riscos de perda total ou frustração de safras de banana na região do Submédio São Francisco, somada ainda à possibilidade de maior retorno econômico, é imperativo o teste de novas técnicas de cultivo da bananeira que resultem no atendimento desses desafios contemporâneos. Diante do exposto, objetivou-se com este trabalho verificar, nas condições do Submédio São Francisco, a resposta do adensamento de plantio na produtividade da cultura de bananeira 'Grande Naine'.

\section{MATERIAL E MÉTODOS}

O experimento foi conduzido na Estação Experimental de Mandacaru, Juazeiro - BA, do Centro de Pesquisa do Trópico Semi-Árido - CPATSA, Embrapa, com as seguintes características climáticas e geográficas: Latitude: $9^{\circ} 24^{\prime} \mathrm{S}$; Longitude: $40^{\circ} 26^{\prime} \mathrm{W}$; Altitude: $375 \mathrm{~m}$; temperatura média: $26,4{ }^{\circ} \mathrm{C}$; evaporação: 7,4 mm*dia ${ }^{-1}$; insolação: $7,3: \mathrm{h}^{*} \mathrm{dia}^{-1}$; umidade relativa: $61,8 \%$. Foram utilizadas mudas oriundas de cultura de tecidos, padronizadas, com tamanho de $30 \mathrm{~cm}$. O plantio foi realizado em 5 de maio de 2000 em um solo argiloso tipo Vertissolo, com as seguintes características químicas médias, encontradas na profundidade de 0-20 cm: H+AL $\left(1,25 \mathrm{cmol}_{\mathrm{c}} \cdot \mathrm{dm}^{-3}\right) ; \mathrm{SB}(25,95$ $\left.\mathrm{cmol}_{\mathrm{c}} \cdot \mathrm{dm}^{-3}\right) ; \mathrm{Ca}\left(22,6 \mathrm{cmol}_{\mathrm{c}} \cdot \mathrm{dm}^{-3}\right) ; \mathrm{Mg}\left(2,9 \mathrm{cmol}_{\mathrm{c}} \cdot \mathrm{dm}\right.$ $\left.{ }^{3}\right) ; \mathrm{K}\left(0,35 \mathrm{cmol}_{\mathrm{c}} \cdot \mathrm{dm}^{-3}\right)$; $\mathrm{Na}\left(0,1 \mathrm{cmol}_{\mathrm{c}} \cdot \mathrm{dm}^{-3}\right)$.

Os espaçamentos utilizados foram empregados no sistema de fila dupla, sendo: $\mathrm{T}_{1}=3,75 \times 1,25 \times 2,0 \mathrm{~m}$ (2.000 pl.ha $\left.{ }^{-1}\right), \mathrm{T}_{2}=3,75 \times 1,25 \times 1 \mathrm{~m}\left(4.000 \mathrm{pl}^{-h^{-1}}\right)$, $\mathrm{T}_{3}=3,75 \times 1,25 \times 0,66 \mathrm{~m}\left(6.060 \mathrm{pl}^{-h^{-1}}\right) ; \mathrm{T}_{4}=3,75 \times$ $1,25 \times 0,50\left(8.000 \mathrm{pl}^{-h^{-1}}\right), \mathrm{T}_{5}=3,75 \times 1,25 \times 2,0 \mathrm{~m}$ (2.000 pl.ha ${ }^{-1}$ ), sendo $3,75 \mathrm{~m}$ entre fileiras duplas, 1,25 $\mathrm{m}$ entre linhas e $2 \mathrm{~m}, 1 \mathrm{~m}, 0,5 \mathrm{~m}$ e $0,66 \mathrm{~m}$ - entre plantas nas linhas. $\mathrm{O}$ tratamento $\mathrm{T}_{5}$ diferenciou-se de $\mathrm{T}_{1}$ (testemunha) no manejo dos perfilhos, o primeiro foi conduzido sem perfilhos até os dez meses de idade; já $\mathrm{T}_{1}$ foi conduzido na forma tradicional de mãe, filha e neta A área total por parcela foi de $70 \mathrm{~m}^{2}(14$ x $5 \mathrm{~m})$; área útil por parcela, $50 \mathrm{~m}^{2}(10 \times 5 \mathrm{~m})$; número de fileiras por parcela: duas; $\mathrm{n}^{\circ}$ de repetições: quatro; área total do experimento: $1960 \mathrm{~m}^{2}$ (56 x $\left.35 \mathrm{~m}\right)$, em delineamento experimental de blocos casualizados.

No plantio, foi aplicado esterco de caprinos de boa qualidade na quantidade de $15 \mathrm{~kg} \cdot \mathrm{m}^{-2}$, mais uma aplicação de superfosfato simples (SS) na quantidade de 375 g.m $\mathrm{m}^{-2}$ no sulco de plantio. Na adubação de crescimento e produção, foram aplicados: $350 \mathrm{~kg} \cdot \mathrm{ha}^{-1} \mathrm{de} \mathrm{N}$, na forma de uréia, $200 \mathrm{~kg} \cdot$ ha $^{-1}$ de $\mathrm{P}_{2} 0_{5}$, na forma de (SS), $870 \mathrm{~kg} \cdot \mathrm{ha}^{-1} \mathrm{~K}_{2}$, na forma cloreto de potássio, $27 \mathrm{~kg} \cdot \mathrm{ha}^{-1}$ de $\mathrm{Ca}$, na forma de nitrato de cálcio, $112 \mathrm{~kg} \cdot \mathrm{ha}^{-1} \mathrm{de} \mathrm{Mg}$, na forma sulfato de magnésio, parcelados a cada 15 dias via fertirrigação, exceto o SS, que foi jogado a lanço aos 90 dias após o plantio. O método de irrigação utilizado foi localizado do tipo gotejamento. A demanda de água da cultura foi baseada na fórmula Etc $=\mathrm{ETA}^{*} \mathrm{Kp}$ $[\mathrm{A}+0,5(1-\mathrm{A})]^{*} \mathrm{Kc} /$ Efi, em que Etc = evapotranspiração da cultura; $A=$ Àrea de cobertura da cultura; ETA = evaporação do tanque classe $\mathrm{A} ; \mathrm{Kp}=$ coeficiente do tanque; Efi = Eficiência do sistema de irrigação; Etc = $\mathrm{ETA}^{*} 0,75 . \mathrm{Kc} / 0,93$. A reposição de lâmina d'agua foi feita diariamente. O Kc foi retirado de Peres Regalado (1974), sendo os seguintes: $1^{\circ}$ e $2^{\circ}$ mês após o plantio $=$ $0,4,3^{\circ}=0,45,4^{\circ}=0,5,5^{\circ}=0,6,6^{\circ}=0,7,8^{\circ}=1,9^{\circ} \mathrm{e}$ $10^{\circ}=1,1,11^{\circ}=0,9,12^{\circ}$ e $13^{\circ}=0,8,14^{\circ}=0,95,15^{\circ}=$ 1,05 .

Foram avaliados o $1^{\circ}$ e $2^{\circ}$ ciclos da cultura. As características avaliadas foram: diâmetro da planta a 30 $\mathrm{cm}$ do solo, altura da planta, massa do cacho, número de pencas, número de frutos, massa do engaço, comprimento do fruto, diâmetro do fruto, massa do fruto, ciclo vegetativo e produtivo (plantio até a colheita), rendimento $\mathrm{ha}^{-1}$, rendimento ha ${ }^{-1}$ ano ${ }^{-1}$. Para efeito de comparação de produtividade (produção por área) no tempo entre os tratamentos, foi utilizada a fórmula $\mathrm{P}^{*} \mathrm{t} / \mathrm{T}$, em que: $\mathrm{P}=$ produção por área $\left(\mathrm{t} \cdot \mathrm{ha}^{-1}\right), \mathrm{t}=$ tempo de referência (12 meses) e $\mathrm{T}=\mathrm{o}$ tempo de produção no campo (meses).

\section{RESULTADOS E DISCUSSÃO}

No primeiro ciclo de produção, apenas as características diâmetro e altura da planta não apresentaram diferenças estatísticas. A massa do cacho em $T_{1}$ e $T_{5}$ $\left(2000\right.$ plantas $\left.\mathrm{ha}^{-1}\right)$ foram superiores às demais, respectivamente com 34 e $32 \mathrm{~kg}$, sendo o T2 (4000 plantas ha-1), $26 \mathrm{~kg}$, superior ao tratamento 4 (8000 plantas ha ${ }^{-1}$ ), com $20,4 \mathrm{~kg}$. O número de frutos acompanhou a tendência do cacho; quanto maior o cacho maior o número de frutos. Quando se comparou a produtividade $\mathrm{ha}^{-1}$ e por ha ${ }^{1}$ ano $^{-1}$, no mesmo tratamento, não se observou diferença, embora em termos absolutos a produtividade em t.ha ${ }^{-1}$ do $\mathrm{T}_{4}\left(8000\right.$ plantas. ha $\left.{ }^{-1}\right)$ tenha passado de $78 \mathrm{t}$ para 63 t.ha $^{-1}$.ano ${ }^{-1}$, devido ao alongamento do ciclo 
nessa densidade populacional. $\mathrm{O} \mathrm{T}_{2}$ (4000 plantas ha $\left.{ }^{-1}\right)$ $\left(98\right.$ t.ha $^{-1}$ e 90 t.ha $^{-1}$ ano $^{-1}$ ) foi superior aos tratamentos $\mathrm{T}_{1}$ e $\mathrm{T}_{5}$, respectivamente $65 \mathrm{t}^{-h^{-1}}$ e 66 t.ha $^{-1} \mathrm{ano}^{-1} 69$ t.ha $^{-1}$ e 68 t.ha $^{-1}$ ano $^{-1}$. O T $\mathrm{T}_{3}$ e $\mathrm{T}_{4}$ não diferiram dos demais tratamentos, respectivamente com 87 t.ha $^{-1}$ e 75 t.ha ${ }^{-1} \cdot$ ano $^{-1}, 78$ t.ha $^{-1}$ e 63 t.ha ${ }^{-1}$.ano ${ }^{-1}$. O ciclo de produção foi menor no $\mathrm{T}_{5}$ e $\mathrm{T}_{1}$ (361 dias) e $\mathrm{T}_{2}$ (396 dias) do que no $\mathrm{T}_{3}$ (422 dias) e $\mathrm{T}_{4}$ (449 dias), conforme Tabela 1.

A qualidade dos frutos aferida pelo diâmetro, comprimento e massa dos frutos foi menor no $\mathrm{T}_{2}(4000$ pl.ha $\left.{ }^{-1}\right)$; entretanto, esse tratamento ainda apresentou boa qualidade comercial dos frutos. Observa-se que os resultados deste experimento foram previsíveis quanto às alterações nas características medidas. Os componentes da produção (cachos, pencas e frutos) foram menores nas maiores densidades, corroborando com as conclusões de Santos (1977), Robinson e Nel (1986), Lichtemberg et al. (1997) e Scarpare Filho e Kluge (2001).

É importante observar que mesmo sendo propósito avaliar o superadensamento da cultura da bananeira para as condições do Submédio São Francisco, isso não ocorreu na prática, pois o maior número de plantas colhidas por hectare foi de 4.004 plantas $\left(\mathrm{T}_{3}-6.060 \mathrm{pl}\right.$. ha $\left.{ }^{1}\right)$. No segundo ciclo, foi ainda menor o número de plantas colhidas, não passando de 3.861 plantas no $\mathrm{T}_{2}$. Esse fato pode ser explicado pelas condições de cultivo da região, onde principalmente o vento danificou a maioria das plantas fracas, impedindo-as de terminarem o ciclo.

Observações feitas in loco mostraram a inadequação do sistema de fileira dupla para plantios adensados. A proximidade das plantas na linha de $0,50 \mathrm{~cm}$ entre plantas no tratamento 4 proporciona forte competição entre elas no início do plantio, impedindo qualquer recuperação futura de uma planta fraca. A densidade final de plantas colhidas nos tratamentos adensados mostra bem esse efeito. Os números finais de plantas colhidas no $2^{\circ}$ ciclo foram $1.859\left(\mathrm{~T}_{1}\right), 3.718\left(\mathrm{~T}_{2}\right), 4.004\left(\mathrm{~T}_{3}\right), 3.861$ $\left(\mathrm{T}_{4}\right)$ e 2.145 plantas $\left(\mathrm{T}_{5}\right)$, respectivamente $93 \%$, 93\%, $67 \%, 48 \%$ e $107 \%$ das plantas da população inicial de cada tratamento. Esses resultados do $2^{\circ}$ ciclo permitem tirar conclusões sobre consequiências do adensamento nas condições locais e do manejo praticado. Por questões administrativas e gerenciais, não foi mantido o manejo preconizado da densidade das parcelas nesse ciclo. Assim, as plantas oriundas das parcelas menos adensadas (mais vigorosas) produziram mais perfilhos/touceira; o contrário acontecendo com as plantas mais fracas (oriundas das den- sidades maiores), em que ocorreu um menor perfilhamento. Esse resultado pode ser observado na Tabela 1, na qual se pode observar que não houve diferenças entre o número de plantas/parcela entre os tratamentos.

No segundo ciclo, as características diâmetro (DP) e altura da planta (AP), diâmetro (DF) e massa do fruto (MF) e rendimento (R.ha ${ }^{-1}$ ) não apresentaram diferenças entre os tratamentos. Já as características massa do cacho, $\mathrm{n}^{\circ}$ de pencas, $\mathrm{n}$. de frutos, massa do ingaço, comprimento do fruto, ciclo e rendimento $\left(\mathrm{ha}^{-1} \cdot\right.$ ano $\left.^{-1}\right)$ foram diferentes entre si. Pode-se observar que os tratamentos menos adensados, $\mathrm{T}_{1}, \mathrm{~T}_{5}$ e $\mathrm{T}_{2}$ ) resultaram em melhor performance em termos de produção, produtividade, menor ciclo e qualidade do fruto. No caso do rendimento $\left(\right.$ R.ha $\left.^{-1}\right)$, não houve diferença entre os tratamentos, apesar da grande diferença absoluta na produção $86 \mathrm{t}\left(\mathrm{T}_{1}\right)$ e 46,5 t $\left(\mathrm{T}_{4}\right)$. A inexistência de diferenças foi devida ao alto coeficiente de variação dessa característica (CV de 25\%). O rendimento ha ${ }^{-1}$ ano $^{-1}$ foi significativo entre os tratamentos porque resultou da combinação das variáveis massa do cacho e ciclo, as quais apresentaram diferenças significativas entre os tratamentos. Nesse caso, o $\mathrm{T}_{1}\left(70 \mathrm{t} \mathrm{ha}^{-1}\right.$ ano $\left.^{-1}\right)$ e $\mathrm{T}_{2}\left(75 \mathrm{t} \mathrm{ha}^{-}\right.$ ${ }^{1}$ ano $\left.^{-1}\right)$ foram superiores ao $\mathrm{T}_{4}\left(52 \mathrm{t} \mathrm{ha}^{-1}\right.$ ano $\left.^{-1}\right)$.

Pelos resultados também pode-se concluir que não houve perda da qualidade do fruto em termos de diâmetro e comprimento do fruto nas densidades efetivas de até 4.000 plantas ha $^{-1}$. Segundo Manica (1997), nos frutos de banana do subgrupo Cavendish, que inclui a cv. Grande Naine, o diâmetro do fruto aceito como de boa qualidade varia de 33 a $38 \mathrm{~mm}$, sendo de $34 \mathrm{~mm}$ ideal para exportação. Quanto ao comprimento, também não houve perda de qualidade, já que a legislação americana estabelece um mínimo de $17 \mathrm{~cm}$ de comprimento na curvatura externa do fruto (ALVES, 1999).

O trabalho também apresenta subsídios para a utilização do adensamento para minimizar os efeitos dos ventos e obter a colheita programada no Submédio São Francisco, na medida em que estabelece comportamento médio das plantas submetidas ao adensamento. Para efeito de recomendação, os melhores tratamentos obtidos no trabalho podem ser referência para esses objetivos.

Na região do Submédio São Francisco, região onde se realizou o experimento, não há ocorrência severa da sigatoka amarela (Mycosphaerella musicola, Leach), portanto, não pode afirmar sobre possíveis vantagens com relação ao controle dessa doença foliar, quando se utiliza o adensamento populacional. 


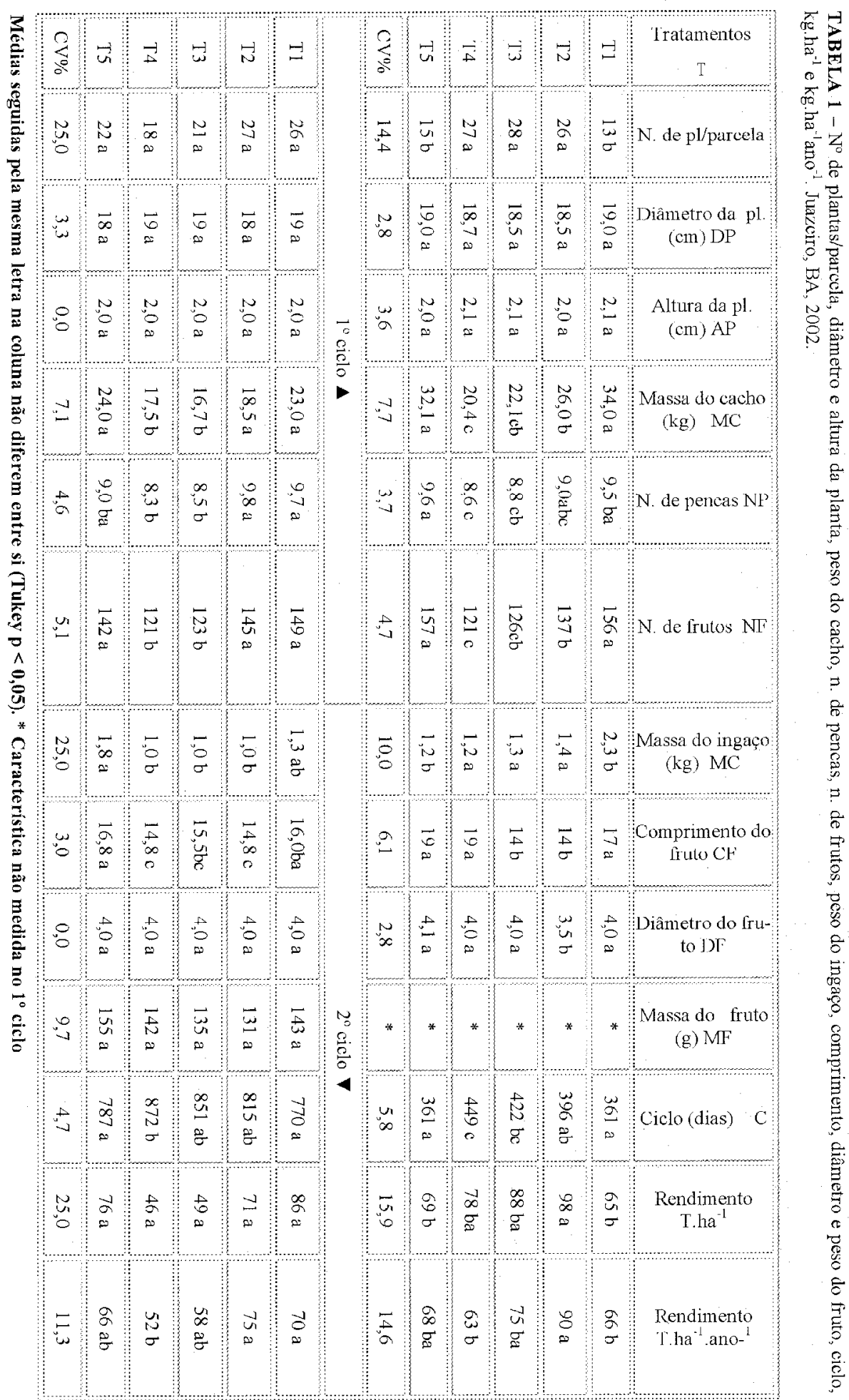

Ciênc. agrotec., Lavras, v. 28, n. 5, p. 1060-1065, set.out., 2004 


\section{CONCLUSÕES}

Concluiu-se que na densidade de 4.000 plantas ha $^{-1}\left(\mathrm{~T}_{2}\right)$ a cultura da bananeira 'Grande Naine' irrigada apresentou, no $1^{\circ}$ ciclo de produção, a melhor performance em termos de rendimento $\left(\mathrm{R} \mathrm{ha}^{-1}\right)$ com $98 \mathrm{t}$. No $2^{\circ}$ ciclo, as densidades de 2000 plantas ha $^{-1}\left(\mathrm{~T}_{1}\right)$ e 4.000 plantas $\mathrm{ha}^{-1}\left(\mathrm{~T}_{2}\right)$ foram superiores no conjunto das características avaliadas, principalmente com relação à massa do cacho e ao rendimento $\left(\mathrm{T} \mathrm{ha}^{-1} \mathrm{ano}^{-1}\right)$, respectivamente 23 e $18,5 \mathrm{~kg}$ e 70 e $75 \mathrm{t} \mathrm{ha}^{-1} \mathrm{ano}^{-1}$.

A densidade de 4.000 plantas $\mathrm{ha}^{-1}\left(\mathrm{~T}_{2}\right)$ poderá ser útil caso o produtor queira concentrar a colheita para épocas pré-definidas, com o intuito de minimizar as quedas causadas pelo vento.

Conclui-se que não houve perda da qualidade do fruto para exportação com relação ao diâmetro do fruto, que foi acima de $40 \mathrm{~mm}$ em todos os tratamentos, nas densidades efetivas de até 4.000 plantas ha ${ }^{-1}$.

\section{REFERÊNCIAS BIBLIOGRÁFICAS}

AGRIANUAL. São Paulo: FNP Consultoria \& Agroinformativos, 2004.

ALVES, E. J. (Org.). A cultura da banana: aspectos técnicos, sócio-econômicos e agro-industriais. 2. ed. Brasília: EMBRAPA-SPI, 1999. 585 p.

ANIL, B. K.; NAIR, C. S. J.; NAIR, S. R.; JAYACHANDRAN-NAIR, C. S.; RAMACHANDRANNAIR, S. Economics of tissue cultured Nendran (AAB) banana under different planting densities. South-IndianHorticulture, [S.1.], v. 42, n. 5, p. 285-288, 1994. Disponível em:Acesso em: 10 nov. $200 \overline{3}$.

BELALCÁZAR CARVAJAL, S. L. El cultivo de plátano em el trópico. Cali: ICA/IDRC/Comitê Departamental de Cafeteros del Quindío/INIBAP, 1991. 376 p.

FAO. Dados agrícolas de FAOSTAT. 2001. Disponível em: 1 agriculture\&language $=\mathrm{ES}>$. Acesso em: 25 nov. 2003.

GOMES, J. A. Propagação e densidade de plantio da bananeira. In: SIMPÓSIO BRASILEIRO SOBRE BANANICULTURA, 1., 1984, Jaboticabal, SP. Anais... Jaboticabal: FCAVJ, 1984. p. 214-233.
LICHTEMBERG, L. A.; HINZ, R. H.; MALBURG, J. L.; STUKER, H. Crescimento e duração dos cinco primeiros ciclos da bananeira 'Nanicão', sob três densidades de plantio. Revista Brasileira de Fruticultura, Cruz das Almas, v. 19, n. 1, p. 15-23, 1997.

LICHTEMBERG, L. A.; MALBRUG, J. L.; HINZ, R. H. Espaçamentos para bananeira Nanicão no Litoral Norte de Santa Catarina. In: CONGRESSO BRASILEIRO DE FRUTICULTURA, 13., 1994, Salvador, BA. Resumos... Salvador: SBF, 1994. v. 1, p. 183-184.

MANICA, I. Fruticultura tropical: 4 banana. Porto Alegre: Cinco Continentes, 1997. 485 p.

MOREIRA, R. S. Banana. In: ENCICLOPÉDIA Agrícola Brasileira. São Paulo: USP, 1995. v. 1, p. 335-354.

PERES REGALADO, A. El riego de la platanera: consideciones de interés para la Isla de Tenerife. Agricultura, Madrid, p. 251-255, 1974.

ROBINSON, J. C.; NEL, D. J. The influence of banana (cv. Williams) plant density and canopy characteristics on ratoon cycle interval and yield. Acta Horticulture, Leuven, n. 175, p. 227-232, 1986.

ROSA JÚNIOR, C.; REI M. del; SAUERESSIG, M. E.; FREIRE, F. de A.; COSTA, F. F. da; SILVA FILHO, A. V. da. Bananeira: cultivo sob condição irrigada. 2. ed. Recife: SEBRAE/PE, 2000. 51 p. (Série Agricultura, 2).

SANTOS, P. J. Estudo do comportamento da bananeira (Musa acuminata, Colla), cv. Nanica em diferentes espaçamentos. 1977. 26 f. Dissertação (Mestrado) - Universidade Federal de Viçosa, Viçosa, 1977.

SCARPARE FILHO, J. A.; KLUGE, R. A. Produção da bananeira "Nanicão" em diferentes densidades de plantas e sistemas de espaçamento. Revista Brasileira de Fruticultura, Brasília, v. 36, n. 1, p. 105-113, 2001.

SILVA, J. F. da; CAMPOS, G. M. Estudos de densidade de plantio em bananeira cultivar "Nanica" em áreas irrigadas do Nordeste Brasileiro. In: CONGRESSO BRASILEIRO DE FRUTICULTURA, 3., 1975, Itaguai. Anais... Itaguai: SBF, 1975. v. 1, p. 19-25.

SOTO BALLESTERO, M. S. Bananos: cultivo y comerialización. 2. ed. Tibás: LIL, 1992. 674 p. 